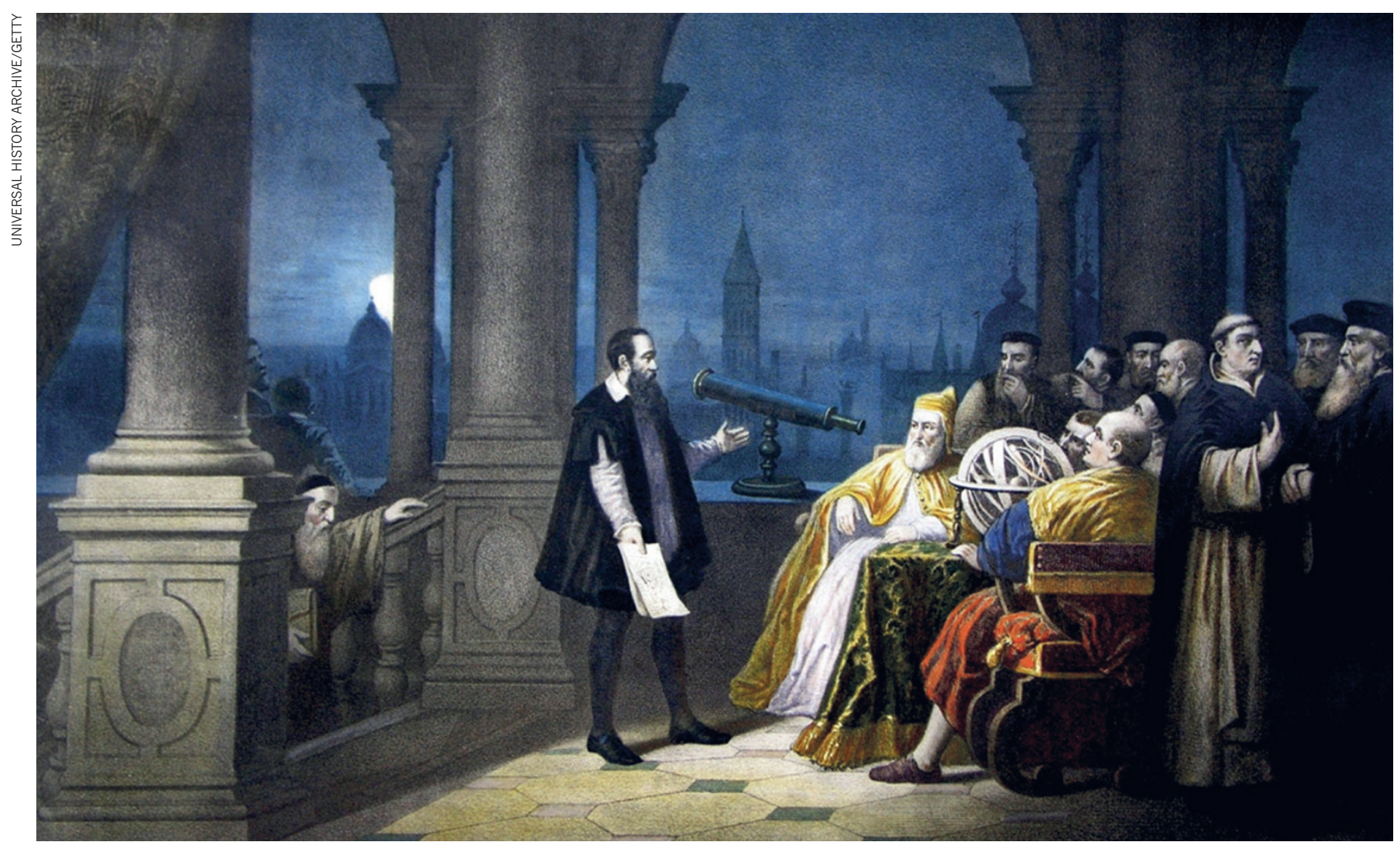

Galileo Galilei, pictured centre, after a painting by H. J. Detouche, is imagined in Giulio Tononi's Phi as an explorer of consciousness.

\title{
NEUROSCIENCE
}

\section{A quest for consciousness}

\section{Christof Koch marvels at a journey that explains mind-body theory through a fantastical lens.}

I $\mathrm{n}$ the end, consciousness is all that matters. So writes Giulio Tononi, whose stunningly original scientific fantasy, $P h i$, is a distant echo of that great deduction by René Descartes. Tononi, a neuroscientist, psychiatrist and expert on sleep and consciousness, is also that rarest of modern scholars - an idealist. In this category-defying book, he presents his quantitative theory of how brain produces mind as a voyage of discovery imagined for Galileo Galilei.

In Tononi's literary telling of this story, Francis Crick teaches Galileo basic neuroscience. Galileo learns that the brain is the seat of the mind, and that consciousness flees when neurons turn on and off together during deep sleep or seizures, as the pair meet scholars, scientists, doctors and artists from the Enlightenment to the modern era. The vast cast includes Descartes, Nicolaus Copernicus, Charles Darwin, Sigmund Freud, Marcel Proust and, eventually, Alan Turing.
Galileo negotiates some tricky concepts on a road long trodden by neuroscientists and neurologists seeking to track consciousness down to its lair in the brain. Even if we could point to this biophysical mechanism, and those nerve cells, as mediators of the phenomenal experience of red, we would still need to ask - why

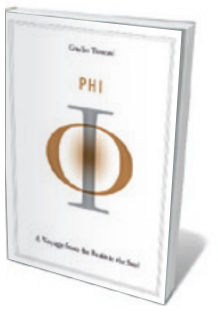

Phi: A Voyage from the Brain to the Soul

GIULIO TONONI

Pantheon: 2012. 384 pp. $119.99, \$ 30$ these particular mechanisms and neurons? Why not others? Historically, the great challenge has been to explain how consciousness emerges from highly organized matter without invoking magic, soul-stuff or exotic physics.

With the advent of Claude Shannon's information theory in the twentieth century, scholars averred a link between information and conscious experience without working out what that might be or could imply. Tononi's integrated-information theory does both. Proceeding from two axioms that are rooted in everyday phenomenal experience, the theory defines a measure (the eponymous $\Phi$ ) that is associated with every system that consists of causally interacting parts. This measure is high if a system constitutes a single entity above and beyond its parts (integration) and if it is endowed with a large repertoire of discriminable states (information). The more integrated information any system has, the more conscious it is. This framework, couched in a probabilistic language, also captures the unique intrinsic quality of experience - why blue, for example, is more similar to red than to pain or smell.

In $P h i$, this is conveyed through a 
series of dazzling thought experiments aided by cameos from Shannon and philosophers Spinoza, Leibniz and Thomas Nagel (the only living person to figure in the book). Through them, Galileo understands how the algebra of integrated information is turned into the geometry of conscious experiences, and how this links to the physiology and the anatomy of the brain.

In the book's final third, Tononi lays out the implications of his theory. He discusses a number of points about consciousness: that it ceases in death and dementia, does not require language or knowledge of self, exists in animals in graded forms and can be present, to some degree, in the fetus.

Hell, Tononi emphasizes, is all in the mind. One of the most chilling characters in Phi is the Master, an amalgam of the captain in Franz Kafka's 1914 short story In the Penal Colony and the Grand Inquisitor from Fyodor Dostoyevsky's novel The Brothers Karamazov (1880). The

Master's obsession

"This is a story for grown men, not a consoling tale for children." is creating perfect never-ending pain by manipulating the brain's informational content. In the final chapter, the Mannequin, a stand-in for Mephistopheles, throws up some logical paradoxes before leaving the dying Galileo reunited with his beloved daughter.

$P h i$ is extraordinary. In its appeal to the imagination, it bears some resemblance to Edwin Abbott's Flatland novella (1884) or Douglas Hofstadter's Gödel, Escher, Bach (Basic Books, 1979). Yet its language is more poetic, and full of cultural references and images - film stills and often modified coloured photos of artworks. Endnotes to each chapter link the allegories and metaphors in the text to the science.

I believe that in the fullness of time, the quantitative framework outlined in $\mathrm{Phi}$ will prove to be correct. Consciousness is tightly linked to complexity and to information, with profound consequences for understanding our place in the evolving Universe. As Crick says to Galileo, this is a "story for grown men, not a consoling tale for children".

Christof Koch is chief scientific officer at the Allen Institute for Brain Science in Seattle, Washington, and professor of biology and engineering at the California Institute of Technology in Pasadena, California.

e-mail:christofk@alleninstitute.org

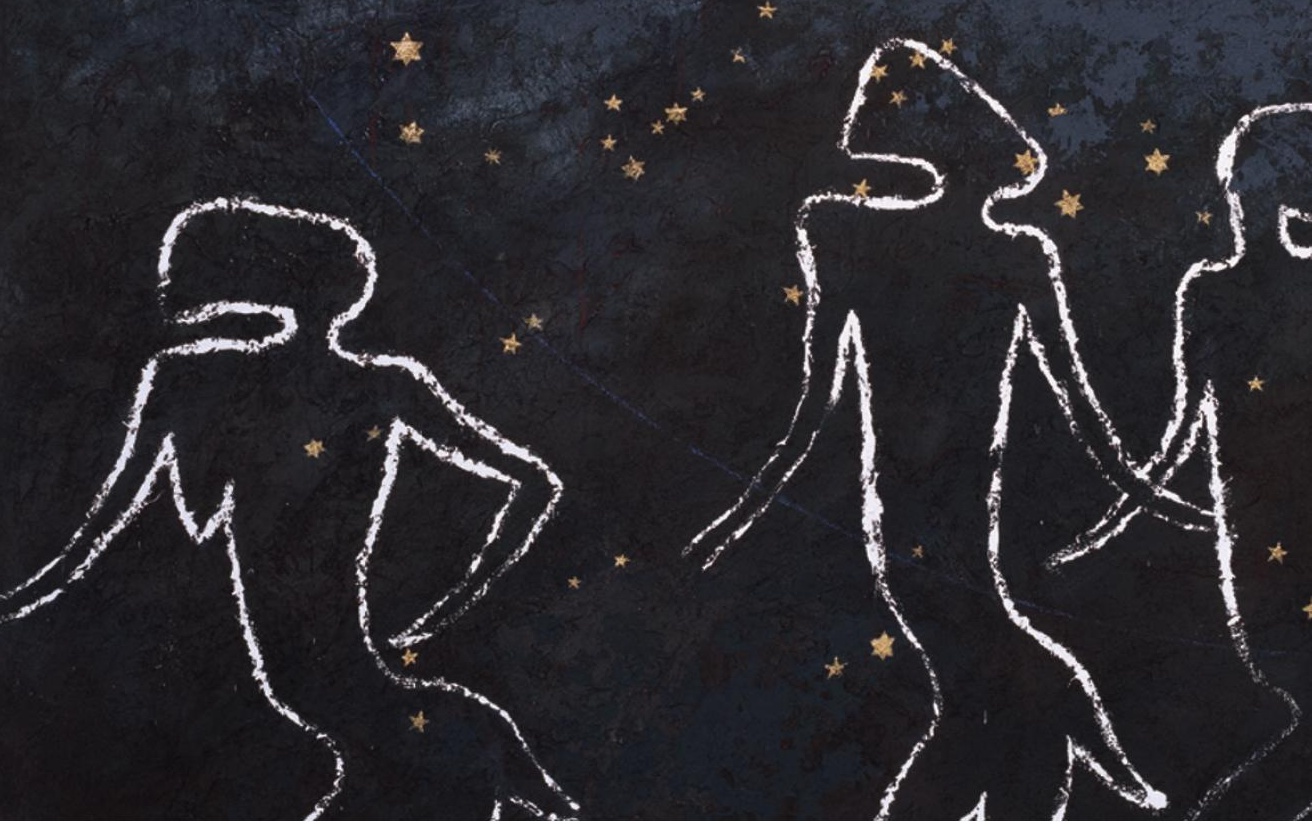

Gavin Jantjes' untitled painting depicts a Khoisan girl creating the Milky Way.

\section{ASTRONOMY}

\section{Under African skies}

\section{Ivan Semeniuk follows the gaze of artists from cultures that have interpreted the heavens for millennia.}

$\checkmark$ azing up at a sky full of stars is one of the most universal of human experiences, cutting across cultures and, one imagines, stretching back to the dawn of humanity. Yet artistic depictions of the heavens in popular culture are predominantly European - from Johann Bayer's engravings of the constellations in his 1603 star atlas Uranometria to the swirling brilliance of Van Gogh's 1889 painting The Starry Night.

An exhibition at the US National Museum of African Art, part of the Smithsonian Institution in Washington DC, may help to change that. It showcases a range of contemporary and historical pieces by African artists. All are connected in one way or another to the Sun, Moon or stars.

African Cosmos: Stellar Arts was sponsored in large part by the government of South Africa.

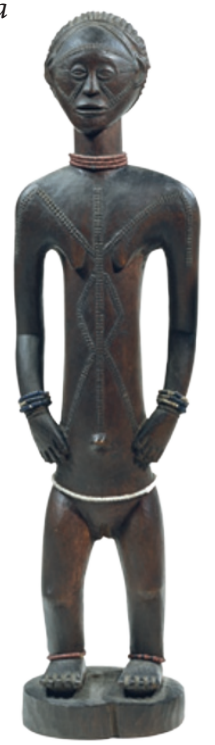

The country was selected this year, along with Australia, to host the Square Kilometre Array, which will be the world's largest radio telescope; that association adds to the sense of interplay between the scientific and the spiritual that weaves its way through the exhibition. The show seamlessly bridges the centuries, uniting pieces as diverse as traditional moon masks from Côte d'Ivoire and Trembling Field, an interactive sculpture by South African Karel Nel. Nel is resident artist with the Cosmic Evolution Survey, a project that focuses on a two-square-degree field of the sky to see how the Universe has changed over time.

"Africa has a long and rich history of keen observation of the heavens," says the exhibition's curator, Christine Mullen Kreamer. "Works

Figures from Central Africa bear lunar patterns. 